\title{
Cutaneous Manifestations at Saphenous Vein Harvest Site among Iraqi Patients with Coronary Artery Bypass Graft
}

\author{
Khalifa E. Sharquie $^{1 \#}$, Adil A. Noaimi ${ }^{2}$, Ali S. Alaboudi ${ }^{3}$ \\ ${ }^{1}$ Iraqi Board for Medical Specializations, Medical Collection Office, Baghdad, Iraq; ${ }^{2}$ Department of Dermatology and Venereology, \\ College of Medicine, University of Baghdad, Baghdad, Iraq; ${ }^{3}$ Department of Dermatology and Venereology, Baghdad Teaching \\ Hospital, Baghdad, Iraq. \\ Email: "ksharquie@yahoo.co.uk
}

Received November $11^{\text {th }}, 2011$; revised December $1^{\text {st }}, 2011$; accepted December $18^{\text {th }}, 2011$

\begin{abstract}
Background: Coronary artery bypass grafting $(\mathrm{CABG})$ has become a common surgical procedure and increasingly done in Iraq. The greater saphenous vein (GSV) is the most veins often used as the conduit and its complications include a variety of cutaneous manifestations. Objective: To report the cutaneous manifestations at the saphenous vein harvesting site in Iraqi patients who undergone CABG. Methods: A total of 100 (82 males, 18 females) patients who had undergone CABG using the saphenous vein (SV) harvested by longitudinal incision open technique at the legs and/ or thighs were included in this case descriptive study. All cases were seen at least two months after the time of the operation in the outpatient clinic of the Cardiac Surgery Department in the Ibn-Albitar Hospital during October 2009 October 2010. A detailed history and close dermatological examination were done including all related points to their problems. Results: The cutaneous changes on and around the saphenous vein (SV) graft donor scars were noticed in 60 out of 100 patients, $49(81.66 \%)$ males and $11(18.33 \%)$ females, their ages ranged from $32-74(59.38 \pm 8.3221)$ years, with body mass index (BMI)ranged from $21.8746-26.9057$ (23.875 \pm 8.5378$)$. The duration interval between the time of CABG and presentation ranged from 2 - 180 months with a median of 5 months, $36(60 \%)$ patients presented at less than 6 months and $24(40 \%)$ patients presented at more than 6 months. Anesthesia was the predominant presenting symptom in $49(81.6 \%)$, followed by neurolgic pain $8(13.3 \%)$ and pruritus $2(3.3 \%)$, while the cutaneous signs recorded at the site of SVG were: Xerosis in $17(28.3 \%)$ patients, followed by residual hyperpigmentation $11(18.3 \%)$, depigmentation 11(18\%), recent hair loss 11 (16.6\%), hypertrophic scar $8(13.3 \%)$, non-healing ulcer $7(11.6 \%)$, lymphedema $7(11.6 \%)$ and neuropathy dermatitis $6(10 \%)$. Conclusions: Cutaneous manifestations following coronary artery bypass surgery are not uncommon problem in Iraqi patients that are seen at area of saphenous vein harvesting but the most interesting thing is to report the neuropathy dermatitis.
\end{abstract}

Keywords: Cutaneous Manifestations; Saphenous Vein; CABG

\section{Introduction}

Coronary artery bypass grafting $(\mathrm{CABG})$ has become a common surgical procedure and increasingly done in Iraq. During this procedure, the greater saphenous vein (SV) is the most often used as the conduit and its complications include a variety of cutaneous manifestations. Cutaneous complications following saphenous vein harvesting for coronary artery bypass grafting are considered minor but may result in significant morbidity [1]. Cellulitis [2,3], non-healing ulcers [4], painful peripheral sensory neuropathy [5] and vein graft dermatitis [6-8] may prompt the patient to seek dermatologic consultation. Specific cutaneous manifestations include dermatitis [6-8], infec-

\footnotetext{
*Disclosure: This study is an independent study and not funded by any of the drug companies.

${ }^{*}$ Corresponding author.
}

tion like cellulitis $[2,3]$, pyoderma gangrenosum $[9,10]$, post stripping sclerodermiform dermatitis [11], saphenous neuralgia [12] and other miscellaneous manifestations include delayed or non-healing wound/ulcer [4], skin/ wound necrosis, abscess, hematoma, lymphocele [13-15], edema [16], xerosis, prurigo, pigmentary alterations, harvesting site depigmentation, pigmented purpuric dermatoses, hypertrophic scar [17] and sweet's syndrome [18].

Aggravating related factors include drugs [19], female [15], diabetes mellitus [15], smoking [19], increased body mass [20,21], pre-operative anemia [21], pre-existing peripheral vascular disease [15], use of intra-aortic balloon pump [22] and operative technique [23-27].

Coincidental cutaneous manifestations; patients who had preexisting dermatoses or concurrent skin involve- 
ment at other body sites may develop a similar lesion along the saphenous vein harvesting sites due to koebner's phenomena like psoriasis, lichen planus. It is rare for eczematous dermatoses to demonstrate the koebner's (isomorphic) phenomenon. However, this may occasionally occur, and eczema may also develop at sites of trauma in individuals who have no past history of eczematous dermatosis [28].

So, the aim of the present work is to report the cutaneous manifestations among Iraqi patients with $\mathrm{CABG}$ at the site of saphenous vein harvesting.

\section{Patients and Methods}

A total one hundred (82 males, 18 females) patients who had undergone CABG using the saphenous vein harvested by longitudinal incision open technique $15-45$ $\mathrm{cm}$ in length at the legs and/or thighs were included in this case descriptive study.

All cases were seen at least two months after the time of operation in the outpatient clinic of the Cardiac Surgery Department in the Ibn-Albitar Hospital during October 2009 - October 2010.

A detailed history was taken from all patients including: age, sex, weight and length of patients were recorded and body mass index (BMI) was calculated for everyone, date of CABG, cutaneous problems (duration, course, site of the lesion, associated symptoms and treatment), history of drugs taken, other skin or systemic diseases, smoking and alcohol intake were reported.

All patients were thoroughly examined clinically and close dermatological examination for saphenous vein harvesting sites regarding type of scar, morphology of any skin lesion along the scar and also the hair along the saphenous vein harvesting site. Sensory examination was done to assess any sensory loss along the course of saphenous nerve using light touch and pin prick test. Digital photographs were taken using SONY ${ }^{\circledR}$ Cyber-Shot T300 10.1 MP for each patient in good illumination.

Formal consent was taken from each patient after full explanation about the nature of the study. Ethical approval was obtained from the Scientific Council of Dermatology and Venereology-Iraqi Board for Medical Specializations.

Statistical analyses were done by using chi-square test to compare between two groups of patients (A and B) with cutaneous manifestations according to the interval duration between time of CABG and time of presentation using EPI-Info version 6, CDC, Atlanta-Georgia, USA.

"Group A = Patients with interval duration less than six months.

"Group B = Patients with interval duration more than six months.

"P value $\leq 0.05$ was considered significant.

\section{Results}

One hundred patients were included in this study, 82 $(82 \%)$ males and $18(18 \%)$ females with male to female ratio were 4.6:1. Their ages ranged from $32-80$ years with a mean \pm SD of $59.32 \pm 8.023803$ years, while their weights ranged from $55-96 \mathrm{~kg}$ with a mean $\pm \mathrm{SD}$ of $68.87 \pm 8.207726 \mathrm{~kg}$, with body mass index (BMI) ranged from 21.484375 to 26.592798 with a mean \pm SD of $23.529412 \pm 8.2077$.

The duration interval between the time of CABG and patients presentation ranged from $2-180$ months with a median of 5 months.

The total number of scars on the legs and/or thighs along the harvested saphenous vein were 229 , the number of scars for each patient ranged from 1 - 4 scars with a mean \pm of SD $2.29 \pm 0.7692$ per patient, 67 (67\%) patients had bilateral scars on both lower limbs, while 33 (33\%) patients had unilateral saphenous vein scar either on right or left lower limb.

The cutaneous changes on and around the SV graft donor scars were noticed in 60 out of 100 patients, 49 $(81.66 \%)$ males and $11(18.33 \%)$ females, their ages ranged from $32-74$ years with a mean \pm of SD $59.38 \pm$ 8.3221 years.

Their body mass index ranged from $21.8746-26.9057$ with a mean \pm of $\mathrm{SD}$ was $23.875 \pm 8.5378$. The duration interval between the time of CABG and presentation ranged from $2-180$ months with a median of 5 months, $36(60 \%)$ patients presented at less than 6 months and 24 $(40 \%)$ patients presented at more than 6 months (Table 1).

There was no significant relation except for post inflammatory pigmentation; depigmentation and recent hair loss are found to be more after six months while non-healing ulcer was more before six months of presentation.

Anesthesia at the saphenous vein harvest site was the predominant presenting symptom in $49(81.6 \%)$ cases, followed by neuralgic pain $8(13.3 \%)$ and pruritus 2 $(3.3 \%)$ cases.

The cutaneous signs recorded at the site of SVG were: Xerosis in 17 (28.3\%) patients, followed by post-inflammatory pigmentation 11 (18.3\%), depigmentation 11 $(18.3 \%)$, recent hair loss $10(16.6 \%)$, hypertrophic scar 8 (13.3\%), non-healing ulcer 7 (11.6\%), lymphedema 7 $(11.6 \%)$ and neuropathy dermatitis $6(10 \%)$ patients (Table 2).

The number of smokers was $12(12 \%)$ patients, alcoholics $2(3.3 \%)$.

The commonest drugs used were aspirin $52(86.6 \%)$ patients, followed by clopidogrel $45(75 \%)$, warfarin 24 (40\%), and diltiazem 21 (35\%) patients (Table 3).

The commonest associated disease was hypertension 
Table 1. Showing the frequency of cutaneous manifestations according to the duration interval between the time of CABG and time of presentation.

\begin{tabular}{|c|c|c|c|c|c|c|c|}
\hline \multirow{2}{*}{ Cutaneous Manifestation } & \multicolumn{2}{|c|}{$\begin{array}{l}\text { Duration less than } 6 \text { months } \\
\quad \text { (No. of patients }=36 \text { ) }\end{array}$} & \multicolumn{2}{|c|}{$\begin{array}{l}\text { Duration more than } 6 \text { months } \\
\quad(\text { No. of patients }=24)\end{array}$} & \multirow[t]{2}{*}{ P Value } & \multicolumn{2}{|c|}{ Total (No. of patients $=60)$} \\
\hline & No. & $\%$ & No. & $\%$ & & No. & $\%$ \\
\hline Anesthesia & 32 & 88.88 & 17 & 70.83 & 0.0766 & 49 & 81.6 \\
\hline Xerosis & 7 & 19.44 & 10 & 41.66 & 0.0612 & 17 & 28.3 \\
\hline Post-inflammatory pigmentation & 3 & 8.33 & 8 & 33.33 & 0.0142 & 11 & 18.3 \\
\hline Depigmentation & 4 & 11.11 & 7 & 29.16 & 0.0268 & 11 & 18.3 \\
\hline Recent hair loss & 3 & 8.33 & 7 & 29.16 & 0.0388 & 10 & 16.6 \\
\hline Hypertrophic scar & 5 & 13.88 & 3 & 12.5 & 0.876 & 8 & 13.3 \\
\hline Non healing ulcer & 7 & 19.44 & 0 & 0 & 0.021 & 7 & 11.6 \\
\hline Lymphedema & 5 & 13.88 & 3 & 12.5 & 0.876 & 8 & 11.6 \\
\hline Neuropathy dermatitis & 4 & 11.11 & 2 & 8.33 & 0.725 & 6 & 10 \\
\hline Atrophic scar & 2 & 5.55 & 1 & 4.16 & 0.808 & 3 & 5 \\
\hline Cellulitits & 1 & 2.77 & 0 & 0 & 0.410 & 1 & 1.6 \\
\hline Icthyosiform & 1 & 2.77 & 0 & 0 & 0.410 & 1 & 1.6 \\
\hline Hypertrichosis & 0 & 0 & 1 & 4.16 & 0.216 & 1 & 1.6 \\
\hline Hematoma & 1 & 2.77 & 0 & 0 & 0.410 & 1 & 1.6 \\
\hline Neuralgic pain & 3 & 8.33 & 5 & 20.83 & 0.162 & 8 & 13.3 \\
\hline Pruritus & 1 & 2.77 & 1 & 4.16 & 0.769 & 2 & 3.3 \\
\hline
\end{tabular}

Table 2. Showing the signs in patients with SV grafting scar.

\begin{tabular}{lcc}
\hline \multirow{1}{*}{\multicolumn{1}{c}{ Sign }} & \multicolumn{2}{c}{$\begin{array}{c}\text { Patients with cutaneous changes } \\
\text { (No. =60) }\end{array}$} \\
\cline { 2 - 3 } & No. & $\%$ \\
\hline Xerosis & 17 & 28.3 \\
Post-inflammatory pigmentation & 11 & 18.3 \\
Depigmentation & 11 & 18.3 \\
Recent hair loss & 10 & 16.6 \\
Hypertrophic scar & 8 & 13.3 \\
Non healing ulcer & 7 & 11.6 \\
Lymphedema & 7 & 11.6 \\
Neuropathy dermatitis & 6 & 10 \\
Atrophic scar & 3 & 5 \\
Cellulitits & 1 & 1.6 \\
Icthyosiform & 1 & 1.6 \\
Hypertrichosis & 1 & 1.6 \\
Hematoma & 1 & 1.6 \\
\hline
\end{tabular}

28 (46.6\%), followed by diabetes mellitus $15(25 \%)$ and varicosities $5(8.3 \%)$. There were no relationships between (drugs, smoking, alcoholics and associated diseases) and cutaneous manifestations.

There were no relationships between (drugs, smoking, alcoholics and associated diseases) and cutaneous manifestations.

Six $(10 \%)$ cases of neuropathy dermatitis were seen. All patients presented with erythematous slightly scaly plaques, non itchy on one side of saphenous vein scar
Table 3. The drug used by patients with SV grafting scar.

\begin{tabular}{|c|c|c|c|c|}
\hline \multirow{2}{*}{ Drug } & \multicolumn{2}{|c|}{$\begin{array}{l}\text { Patients with cutaneous changes } \\
\qquad \text { No. }=60)\end{array}$} & \multicolumn{2}{|c|}{$\begin{array}{l}\text { All patients } \\
(\text { No. }=100)\end{array}$} \\
\hline & No. & $\%$ & No. & $\%$ \\
\hline Aspirin & 52 & 86.6 & 91 & 91 \\
\hline clopidogrel & 45 & 75 & 82 & 82 \\
\hline Warfarin & 24 & 40 & 43 & 43 \\
\hline Atenolol & 20 & 33.3 & 33 & 33 \\
\hline Diltiazem & 21 & 35 & 29 & 29 \\
\hline Glibenclamide & 3 & 5 & 9 & 9 \\
\hline Enalpril & 7 & 11.6 & 9 & 9 \\
\hline Insulin & 5 & 8.3 & 9 & 9 \\
\hline Fluvastatin & 6 & 10 & 7 & 7 \\
\hline Co-amilozide & 5 & 8.3 & 6 & 6 \\
\hline Amiloride & 1 & 1.6 & 5 & 5 \\
\hline Metformin & 2 & 3.3 & 4 & 4 \\
\hline Simvastatin & 1 & 1.6 & 2 & 2 \\
\hline Ranitidine & 0 & 0 & 2 & 2 \\
\hline Captopril & 1 & 1.6 & 1 & 1 \\
\hline Carvedilol & 1 & 1.6 & 1 & 1 \\
\hline Frusemide & 1 & 1.6 & 1 & 1 \\
\hline Amiodarone & 2 & 3.3 & 2 & 2 \\
\hline Digoxin & 1 & 1.6 & 1 & 1 \\
\hline Amlodipine & 1 & 1.6 & 1 & 1 \\
\hline Lisnopril & 1 & 1.6 & 1 & 1 \\
\hline Folic acid & 0 & 0 & 1 & 1 \\
\hline Atorvaststin & 1 & 1.6 & 1 & 1 \\
\hline
\end{tabular}




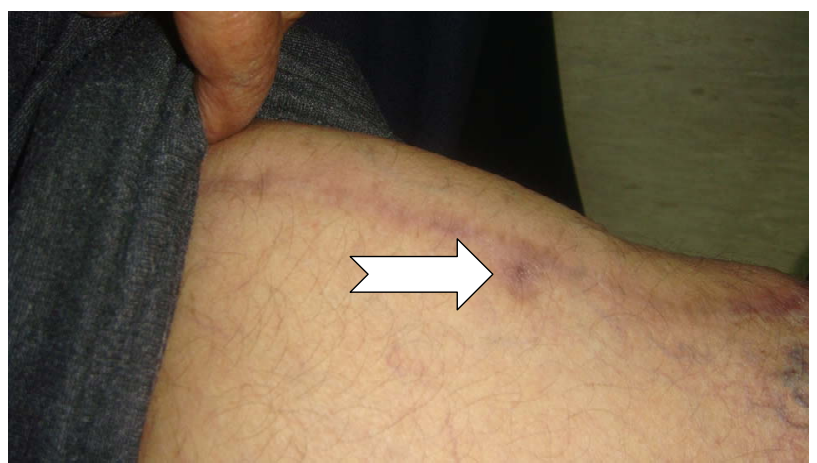

Figure 1. A 66 years old male presented with neuropathy dermatitis on the left leg 5 months after CABG.

usually on anesthetic area (Figure 1). The rash persisted for few weeks and disappeared either spontaneously or treated with topical therapy and left post inflammatory hyperpigmentation.

Five $(83.3 \%)$ males and one (16.67\%) female with male to female ratio 5:1. Their age ranged from 50 - 66 years with a mean \pm SD of $57.6 \pm 6.066$ years and body mass index with mean \pm of SD was $22.87 \pm 8.0658$ years. The duration interval between time of CABG and time of presentation ranged from $2-8$ months with a mean \pm of SD $5 \pm 2.54951$ months.

\section{Discussion}

Cutaneous manifestations that follow coronary artery bypass surgery are not uncommon problem but unfortunately have not been recorded in Iraqi medical literatures [1,13-16,20,29,30].

The present work showed many signs and symptoms that follow saphenous vein harvesting but the main features were anesthesia $(81.6 \%)$, xerosis $(28.3 \%)$, post inflammatory pigmentation (18.3\%), depigmentation (18.3), recent hair loss $(16.6 \%)$, hypertrophic scar $(13.3 \%)$, neurologic pain $(13.3 \%)$, non healing ulcer $(11.6 \%)$, lymphedema (11.6\%), neuropathy dermatitis $(10 \%)$. These manifestations were comparable to many features with other reported studies $[1,13,15,16,20,31]$ mainly the Indian publication [16] where the main features are pruritus (54.1\%), eczematous reaction (38\%), xerosis $(33.33 \%)$, pigmentary alteration $(14.3 \%)$, neuralgic pain $(9.5 \%)$, harvesting site depigmentation (9.5\%) and hypertrophic scar $(4.8 \%)$, unlike the Indian publications there was a relationship between the duration after $\mathrm{CABG}$ and some cutaneous manifestations like: post inflammatory pigmentation, depigmentation and recent hair loss are found to be more after six months while non-healing ulcer was more before six months of presentation.

Most of the literatures related to the present problems were mainly case reports describing single clinical manifestation rather than comprehensive studies as similar to the present work $[2,6,9,11,18,31-33]$.

These signs and symptoms that were recorded in the present work and in comparison with other reports might sustained for a time and disappeared spontaneously and this might taken weeks to several years especially the neuropathy as the anesthesia at the area of saphenous vein harvesting could be persisted for longer time. Regarding drugs intake in those patients with $\mathrm{CABG}$, we think play no role in the cutaneous manifestations whether signs and symptoms.

Neuropathy Dermatitis: Dermatitis has been described at the area of nerve incision following knee surgery and coronary artery bypass surgery at saphenous vein harvest site but this clinical picture has been not well described and defined [6-8,31-33]. Most recently Sharquie had described these conditions very well and gave full explanation for this skin problem and the term neuropathy dermatitis has been invented $[34,35]$. This variant of dermatitis appeared at the site of surgical incision that follow saphenous vein harvesting of the leg and the area of knee replacement surgery. The rash appeared around few 2 - 3 months following the surgery and characterized by welldefined plaque of dermatitis located at the area of sensory loss and at one side of incision and does not cross to other side.

The rash is non-itchy and self-limiting and stays for short time usually weeks-month and then subsided with or without topical steroid therapy and never recurs again $[34,35]$. The present work reported six cases; their features were similar to that of Sharquie reports [34,35].

The mechanism and pathophysiology of this so called neuropathy dermatitis is difficult to explain but we can speculate that at the time of nerve regeneration there will be release of many neuropeptides from the nerve terminals, and these neuropeptides that are released during nerve regeneration like substance $\mathrm{P}$, CGRP, VIP and neurotensin are involved in the regulation of epidermal antigen presentation [36]. These neuropeptides like substance $\mathrm{P}$ appear to play a role in both immediate and delayed-type hypersensitivity reactions in the skin. Substance $\mathrm{P}$ has been demonstrated to participate in or modulate immediate type skin hypersensitivity reactions [36].

In conclusion, cutaneous manifestations following coronary artery bypass surgery are not uncommon problem in Iraqi patients that seen at the area of saphenous vein harvesting and these were mainly: anesthesia, neurologic pain, pruritus, xerosis, hyperpigmentation, hair loss, hypertrophic scar and neuropathy dermatitis.

\section{REFERENCES}

[1] J. Lavee, J. Schneiderman, S. Yorav, M. Shewachmillet and R. Adar, "Complications of Saphenous Vein Har- 
vesting Following Coronary Artery Bypass Surgery," The Journal of Cardiovascular Surgery, Vol. 30, No. 6, 1989, pp. 989-991.

[2] L. M. Baddour and A. L. Bisno, "Recurrent Cellulitis after Saphenous Venectomy for Coronary Bypass Surgery," Annals of Internal Medicine, Vol. 97, No. 4, 1982, pp. 493-496.

[3] P. Kuan, S. B. Bernstein and M. H. Ellestad, "Coronary Artery Bypass Surgery Morbidity," Journal of the American College of Cardiology, Vol. 3, No. 6, 1984, pp. 1391-1397. doi:10.1016/S0735-1097(84)80276-4

[4] L. A. Scher, R. H. Samson and A. Kelosugbo, "Prevention and Management of Ischemic Complications of Vein Harvest Incisions in Cardiac Surgery-Case Reports," Angiology, Vol. 37, No. 2, 1988, pp. 119-123.

[5] R. Adar, K. Meyer and A. A. Zweig, "Complication of Vascular Reconstructions below the Inguinal Ligament," Annals of Surgery, Vol. 190, No. 5, 1979, pp. 609-613. doi:10.1097/00000658-197911000-00008

[6] S. L. Matarasso and T. Rosen, "Leg Dermatitis," Archives of Dermatology, Vol. 126, No. 3, 1990, pp. 385-390.

[7] R. S. Bart, "Dermatitis at Vein Graft Site," Archives of Dermatology, Vol. 119, No. 2, 1983, pp. 97-98. doi:10.1001/archderm.1983.01650260005003

[8] R. D. Can and R. C. Rau, "Dermatitis at Vein Graft Site in Coronary Artery Bypass Patients," Archives of Dermatology, Vol. 117, No. 12, 1981, pp. 814-815. doi:10.1001/archderm.117.12.814

[9] V. A. Sebastian, B. T. Carroll and M. E. Jessen, "Pyoderma Gangrenosum Associated with Chronic Artery Bypass Graft Surgery," Interactive Cardiovascular and Thoracic Surgery, Vol. 10, No. 1, 2010, pp. 135-137. doi:10.1510/icvts.2009.213512

[10] G. Mariscalco, G. Piffaretti, S. Ferrarese and M. Tozzi, "Cattaneo Surgery: A Case Report of Pyoderma Gangrenosum," Journal of Cardiac Surgery, Vol. 24, No, 1, 2009, pp. 93-97. doi:10.1111/j.1540-8191.2008.00728.x

[11] L. E. French, R. Braun, I. Masouye, A. A. Ramolet, P. G. Humbert and J. H. Saurat, "Post-Stripping Sclerodermiform Dermatitis," Archives of Dermatology, Vol. 135, No. 11, 1999, pp. 1387-1391. doi:10.1001/archderm.135.11.1387

[12] J. L. Mountney and G. A. Wilkinson, "Saphenous Neuralgia after Coronary Artery Bypass Grafting," European Journal of Cardio-Thoracic Surgery, Vol. 16, No. 4, 1999, pp. 440-443. doi:10.1016/S1010-7940(99)00294-8

[13] C. E. Paletta, D. B. Huang and A. C. Flore, "Major Leg Wound Complications after Saphenous Vein Harvest for Coronary Revascularization," The Annals of Thoracic Surgery, Vol. 70, No. 2, 2000, pp. 492-497. doi:10.1016/S0003-4975(00)01414-4

[14] S. W. Wong, D. Dernado and P. Grant, "Leg Wound Infections Associated with Coronary Revascularization," Australian and New Zealand Journal of Surgery, Vol. 67, No. 10, 1997, pp. 689-691. doi:10.1111/j.1445-2197.1997.tb07110.x

[15] M. A. Goldsborough, M. H. Miller and J. Gibson, "Prevalence of Leg Wound Complications after Bypass Grafting;
Determination of Risk Factors," American Journal of Critical Care, Vol. 8, No. 3, 1999, pp. 149-153.

[16] C. E. Q. Belczak and A. L. Tyszka, "Clinical Complications of Limb Undergone Harvesting of Great Saphenous Vein for Coronary Artery Bypass Grafting Using Bridge Technique," Revista Brasileira de Cirurgia Cardiovascular, Vol. 24, No. 1, 2009, pp. 68-72. doi:10.1590/S0102-76382009000100013

[17] S. K. Ghosh and D. Bandyopadhyay, "Saphenous Vein Harvesting Site Dermatoses in Eastern India," Dermatology Online Journal, Vol. 15, No. 7, 2009, p. 13.

[18] K. Rikitake, M. Sato, S. Ohtsubo and T. Itoh, "Sweet Syndrome after Off-Pump Coronary Artery Bypass Grafting," Kyobu Geka, Vol. 62, No. 3, 2009, pp. 211-213.

[19] W. H. Frishman and B. D. Brosnan, "Adverse Dematologic Effects of Cardiovascular Drug Therapy; Part I." Cardiology in Review, Vol. 10, No. 4, 2002, pp. 230-246.

[20] G. A. Delaria, J. A. Hunter and M. D. Goldin, "Leg Wound Complications Associated with Coronary Revascularization," Journal of Thoracic and Cardiovascular Surgery, Vol. 81, No. 3, 1998, pp. 403-407.

[21] J. R. Utley, M. E. Thomason and D. J. Wallace, "Preoperative Correlates of Impaired Wound Healing after Saphenous Vein Excision," Journal of Thoracic and Cardiovascular Surgery, Vol. 98, No. 1, 1989, pp. 147-149.

[22] D. J. Mackenzie, N. H. Wagner and D. A. Kulber, "Vascular Complications of the Intra-Aortic Balloon Pump," The American Journal of Surgery, Vol. 164, No. 5, 1992, pp. 517-521. doi:10.1016/S0002-9610(05)81192-4

[23] K. D. Harvath, D. Gray, J. Hill and L. L. Swanstrom, "Operative Outcomes of Minimally Invasive Saphenous Vein Harvest," The American Journal of Surgery, Vol. 175, No. 5, 1998, pp. 391-539. doi:10.1016/S0002-9610(98)00044-0

[24] K. B. Allen and G. L. Griffth, "Endoscopic versus Traditional Saphenous Vein Harvesting," The Annals of Thoracic Surgery, Vol. 66, No. 1, 1998, pp. 26-31. doi:10.1016/S0003-4975(98)00392-0

[25] P. A. Carpino, K. R. Khabbaz and R. M. Bojar, "Clinical Benefits of Endoscopic Vein Harvesting in Patients with Risk Factors for Saphenectomy Wound Infection Undergoing Coronary Artery Bypass Grafting," The Journal of Thoracic and Cardiovascular Surgery, Vol. 199, No. 1, 2000, pp. 69-75. doi:10.1016/S0022-5223(00)70219-4

[26] B. Marty, L. K. Vonsegesser and P. Tozzi, "Benefits of Endoscopic Vein Harvesting," World Journal of Surgery, Vol. 24, No. 9, 2000, pp. 1104-1108. doi: $10.1007 / \mathrm{s} 002680010178$

[27] K. B. Allen and E. B. Fitzgerald, "Management of Closed Space Infections Associated with Endoscopic Vein Harvest," The Annals of Thoracic Surgery, Vol. 69, No. 3, 2000, pp. 960-961. doi:10.1016/S0003-4975(99)01532-5

[28] J. Berth-Jonez, "Eczema, Lichenifi Cation, Prurigo and Erythroderma," In: T. Bums, S. Breathnach, N. Cox and C. Cariffins, Eds., Rook's Textbook of Dermatology, 8th Edition, Chapter 23, Wiley, New York, 2010, pp. 23-28.

[29] M. Dan, K. Heller and I. Shapira, "Incidence of Erysipelas Following Venectomy for Coronary Artery Bypass 
Surgery," Infection, Vol. 15, No. 2, 1987, pp. 107-108. doi:10.1007/BF01650207

[30] A. M. Budillon, G. Zoffoli, A. Agostinelli, S. Congiu, C. Beghi and T. Gherli, "Neurologic Symptoms after Great Saphenous Vein Harvesting for Coronary Artery Bypass Grafting," Journal of Cardiothoracic Surgery, Vol. 44, No. 6, 2003, pp. 707-711.

[31] R. Rai, C. R. Srinivas and K. Vardharaj, "Saphenous Vein Graft Dermatitis in Patient with Coronary Artery Bypass Graft," Indian Journal of Dermatology, Venereology and Leprology, Vol. 74, No. 3, 2008, pp. 278-279. doi:10.4103/0378-6323.41391

[32] L. L. Hruza and G. J. Hruza, "Saphenous Vein Graft Donor Site Dermatitis. Case Reports and Literature Review," Archives of Dermatology, Vol. 129, No. 5, 1993, pp. 609-
612. doi:10.1001/archderm.129.5.609

[33] N. Kato and H. Veno, "Saphenous Vein Graft Donor Site Dermatitis in Japan," The Journal of Dermatology, Vol. 22, No. 9, 1995, pp. 681-685.

[34] K. E. Sharquie, "Post-Bypass Dermatitis," VGRD. Blog, 10 October 2009.

[35] K. E. Sharquie, "Neuropathy Dermatitis," VGRD. Blog, 22 June 2010.

[36] D. Roosterman, T. George, S. W. Schneider, N. W. Bennett and M. Steinhoff, "Neuronal Control of Skin Function: The Skin as a Neuroimmunoendocrine Organ," Physiological Reviews, Vol. 86, No. 4, 2006, pp. 1309-1379. doi:10.1152/physrev.00026.2005 